\title{
Transdiagnostic Factors Across Eating Disorders: A Clinical Review
}

\author{
Kexin $\mathrm{Fu}^{1, *}$ \\ ${ }^{1}$ Enter Author Affiliation 1 University of California, Irvine \\ *Corresponding author. Email: fuk2@uci.edu
}

\begin{abstract}
The symptoms of maladaptive eating behaviour are different across eating disorders due to varying degrees of transdiagnostic factors, such as emotional regulation abilities, impulsiveness, perfectionism, and cognitive control. This paper shows that patients who failed to control their eating behaviours were more impulsive and less effective at regulating their emotions than those who over-controlled their eating habits. Furthermore, the implications of this paper indicate that psychologists should pay attention to the benefits that transdiagnostic factors in mental disorders can bring to treatment.
\end{abstract}

Keyword: Eating Disorder, Transdiagnostic Factors, Impulsiveness, Emotional Regulation, Anorexia Nervosa, Binge Eating Disorder

\section{INTRODUCTION}

Eating disorders are mental disorders which are characterized by abnormal eating behaviors that negatively affect individuals' physical and mental health. Many researchers believe that eating disorders can be viewed as a "pathological self- and bodily-control" disorder [1].

Anorexia Nervosa (AN) is a type of eating disorder which is characterized by restriction of energy intake and weight loss. Individuals with Anorexia Nervosa have distorted attitudes toward their body image: they overvalue "thinness" and have strong fears about being "fat" or overweight despite low body weight [2]. Patients with Anorexia Nervosa are often categorized into two subtypes: restricting type (AN-R) and binge eating/purging type (AN-BP). People with AN-R always show a high degree of unhealthy control over their eating behaviors. They use this maladaptive amount of selfcontrol to help them starve themselves in order to improve self-esteem and gain the feeling of success [3]. Alternatively, people who suffer from AN-BP are also very restrictive eaters with low weight who sometimes show a loss of control of their eating behaviors, but quickly compensates for their binge eating by purging. Bulimia Nervosa (BN) is also a kind of eating disorder which displays binge eating and purging symptoms as seen in AN-BP, but without low body weight.
Binge eating disorder (BED) is another kind of eating disorder which is characterized by compulsive overeating. People with BED have episodes of binge eating wherein they consume a larger than normal amount of food accompanied by a sense of loss of control [4]. Binge eating in the absence of weight-compensatory behaviors leads many patients with BED to be overweight or obese and many patients report a feeling of compulsive urge to binge eating no matter how many times they vowed to stop [5]. Research has shown that there is a significant correlation between loss of control and binge eating episodes [6]. Further, a longitudinal study shows that most patients reported loss of control experiences during overeating episodes, so the researchers believe that losing control of eating should be considered a unique and important diagnostic criterion of binge eating disorder [7].

$\mathrm{AN}, \mathrm{BN}$ and BED are all known as eating disorders with many shared features: they all share distorted beliefs about their body image and show problematic self-control over one's actions and thoughts to varying degrees. But they also have distinct underlying mechanisms, such as the occurrence of binge eating episodes or restricting episodes. Some researchers believe that binge eating episodes (AN-P, BN, BED) are the result of loss control of eating, while over control of eating can lead to restricting episodes (AN-R). What factors may account for this difference? In this review paper, I will discuss how cognitive control, impulsivity, emotion regulation, 
and perfectionism may be transdiagnostic processes that vary across eating disorders. I will discuss how these processes may be especially important to target in treatment.

\section{COGNITIVE CONTROL}

One of the explanations for the strong control over diet of individuals with Anorexia Nervosa is that these patients have difficulties in gaining perceived control in the general life. They believe that they have almost no control over what happens around them and feel powerless when they are facing their own problems [8]. Research shows that patients with Anorexia Nervosa report feeling less control of events and are more likely to attribute the cause of negative events to themselves [1]. According to Slade's theory, this is because they perceived no or only a little bit of personal control over events in their life, so they want to reduce the lack of control in their daily lives by being fully in control of at least one aspect of their life, which is their eating behavior [9]. This kind of "general life dissatisfaction" leads to an idealized feeling of total success related to eating behaviors [1]. Research also found that patients with Anorexia Nervosa usually report a higher level of fear of losing self-control than people without any kinds of eating disorders [10]. These patients tend to score high on control and constraint personality dimensions. The personality dimensions of individuals with Anorexia Nervosa reflect a higher than normal self-discipline, selfcontrol ability, and inhibition of emotionality [11]. One research study found that the inflexible thinking style and rigid behavior patterns of Anorexia Nervosa patients also experience a lower sense of control of eating behaviors. Some researchers have proposed that Anorexia Nervosa can be viewed as an excessive cognitive control-related disorder [12].

\section{IMPULSIVITY IN EATING DISORDERS}

Impulsive traits also play a crucial role within eating disorder patients. Impulsive individuals like the pursuit of excitement and it is difficult to control their momentary emotions. Impulsivity encompasses multiple dimensions rather than only has one single aspect. There are two independent factors that have been shown to be included in impulsivity: reward sensitivity and rash spontaneously impulsively [13]. Reward sensitivity refers to a person's tendency to detect and seek reward from positive stimuli, while rash spontaneously impulsively refers to the tendency to respond after adequately assessing the context $[14,15]$. Research shows that patients with eating disorders, especially those characterized by binge eating episodes, scored high on both rash-spontaneous impulsiveness and reward sensitivity. For patients with binge eating episodes, reward sensitivity may result in greater sensitivity toward food, on the other hand, rash spontaneous impulsively might contribute to the inability to inhibit, loss of control of their eating behaviors and inability to resist binge craving [13]. A Heightened reward sensitivity likely leads to a higher level of abnormal eating behaviors, especially within bulimic women [16].

Bingeing-type eating disorders and restricted-type eating disorders are considered to exist at two endpoints of impulsive personality which can be distinguished by the degree of impulsivity [17]. Research found that patients with AN tend to score lower on impulsiveness and venturesomeness personality than healthy people; however, they made more impulsive choices during a behavioral test. These findings led to a result that selfreported self-control and impulsive behaviors can occur simultaneously within an individual with AN-R. The absence of general response inhibition may result in the development of specific eating disinhibition [18]. However, there is a high prevalence of impulsive behaviors for individuals with binging type eating disorder: AN-BP, BN, and BED [19]. One study reported that people with AN-BP, BN display a higher probability of engaging in risk behaviors, such as stealing and substance abuse [19]. Additionally, motor impulsiveness was higher for bingeing patient groups, and people with $\mathrm{AN}-\mathrm{BP}$ and $\mathrm{BN}$ were more likely to make errors during behavioral measurements than people with AN-R [20]. Accordingly, it is possible that patients with AN-R are less impulsive than both patients with AN-BP and BN [21].

\section{EMOTION REGULATION}

Maladaptive emotion regulation is found across eating disorders [22]. Some researchers believe that abnormal eating habits are ineffective coping strategies for emotional regulation, and that the inability to detect one's emotional state will lead to problematic eating behaviors [23,24]. Patients with AN have difficulties with both detection and regulation of their emotions, so researchers hypothesize that they are doing excessive exercise and restricting food intake in order to reduce their negative feelings [25]. It has also been suggested that alexithymia, a personal trait which is marked as inability to aware and identify emotions, is more common within individuals with AN [26]. Furthermore, for patients with binge eating episodes, such as BN and BED, their compulsive binge eating behaviors are thought to be related with problematic impulsive control of both negative and positive emotions [27]. Research shows that the increase of binge eating episodes often occurs after negative emotional states for patients with $\mathrm{BN}$ and BED [28]. Across studies, the inability to detect and control one's emotion is considered as a transdiagnostic risk factor across all eating disorders.

However, there is a significant difference in emotional regulation between different types of eating disorders. The results conclude that people with binge 
eating type eating disorder (BN/BED) are more likely to have the inability to regulate their emotions than people with restricting type eating disorder (AN-R; 22). This may be due to alexithymia that has been observed in AN. Nonetheless, this research supports a theory that the frequency of distorted eating behaviors is correlated with severity of emotional regulation, by showing that patients with lower ability to regulate emotions had a poorer treatment outcome than those with higher ability. Accordingly, severity of emotion disregulation may be related to eating disorder severity and treatment outcome [22].

\section{PERFECTIONISM}

Perfectionism is a transdiagnostic process that may maintain psychopathology among different eating disorders [29]. Researchers believe that perfectionism can both be perceived as a self-focused structure and also includes interpersonal components: people with high perfectionism not only show high standards of achievement and are often critical of themselves when failing to meet their standards, but also have unrealistic high expectations toward other people [30,31]. Individuals with eating disorders have higher levels of perfectionism than other mental disorder groups [32]. The relationship between $\mathrm{AN}$ and perfectionism has been accepted for a long time, while the linkage with $\mathrm{BN}$ is less clear. However, a systematic literature review shows that patients with AN and BN scored higher on perfectionism than people without the disorders. Moreover, perfectionism traits are related with later development of $\mathrm{BN}$ and predict increases in binge eating episodes among female patients [33]. Patients with $\mathrm{AN}$ and $\mathrm{BN}$ have significantly higher standards toward their eating behaviors and general life than patients with other kinds of mental disorders [34]. There are no significant differences of levels of perfectionism have been observed between different eating disorders subtype, while among a non-depressed AN group, there is some evidence indicating that patients with binge eating episodes scored higher on perfectionism than patients with restricting eating behaviors only [35].

\section{DISCUSSION}

$\mathrm{AN}, \mathrm{BN}$ and BED are all eating disorders that have a lot in common, but their overt symptoms and covert internal mechanisms are likely different. In summary, patients with binge eating episodes, such as BED, BN and AN-BP are more impulsive and more incapable of regulating emotions than individuals with restricting type eating disorder AN-R. In contrast, the extent of perfectionism differs minimally across different types of eating disorders. From this we can see that people with binge eating disorders, whether they tend to over-control their eating behaviors or lose control of their eating behaviors, whether they have binge eating episodes or restricting episodes, all of these disorders involve the experience of having limiting control over their general life.

From this research, we can see that there are many additional transdiagnostic maintaining processes that contribute to the core eating disorder symptoms. If psychologists not only focus on maladaptive eating behavior, but also integrate all the factors comprehensively, it is likely that there will be a breakthrough in the treatment of eating disorders. This review paper has interesting clinical implications: by understanding all those underlying transdiagnostic factors between all kinds of eating disorders, it will be more practical and effective to treat these disorders via adopting transdiagnostic than applying several disorder specific interventions [36]. We predict that an early focus on overlapping and different aspects of cognitive control, impulsivity, emotional regulation and perfectionism between each type of eating disorder would lead to a better treatment outcome. Further investigation across different disorders also required in future research. Future work should test the hypothesis directly through meticulously clinical experiments. For example, behavioral tests should be designed to measure impulsivity, perfectionism, and their ability to regulate emotions, rather than just using self-report questionnaires results as a basis for conclusions. It is also important to consider the correlation between different transdiagnostic factors so we also need to design new experiments to distinguish the correlation between those variables.

\section{CONCLUSION}

In sum, the causes of distorted diet behavior of patients with eating disorders are related to different kinds of transdiagnostic factors, such as cognitive control, impulsivity, perfectionism and emotional regulation. AN-R patients had excessive control over their eating behaviors, while patients with binge eating episodes (AN-B, BN, BED) sometimes had no control over their eating behaviors. This may be due to the different effects of transdiagnostic factors on patients with different eating disorders. While future research is needed, this paper can help us to deepen our understanding of including transdiagnostic factors as a part of our mental disorder treatment.

\section{DECLARATIONS}

Ethics approval and consent to participate: Not applicable.

Consent for publication: Not applicable

Availability of data and materials: Not applicable

Competing interests: KF does have any competing interests to disclose. 
Funding: This paper is not associated with any funding sources.

Authors' contributions: KF conducted the literature review and wrote this review.

Acknowledgements: This paper was written as part of an educational program sponsored by ViaX.

\section{REFERENCES}

[1] Dalgleish T, Tchanturia K, Serpell L, Hems S, de Silva P, Treasure J. Perceived Control Over Events In The World In Patients With Eating Disorders: A Preliminary Study. Personality and Individual Differences. 2001 Aug 1;31(3):453-60.

[2] Bulik CM, Sullivan PF, Tozzi F, Furberg H, Lichtenstein P, Pedersen NL. Prevalence, Heritability, and Prospective Risk Factors For Anorexia Nervosa. Archives of General Psychiatry. 2006 Mar 1;63(3):305-12.

[3] Bruch H. Preconditions for The Development of Anorexia Nervosa. The American Journal of Psychoanalysis. 1980 Jun 1;40(2):169-72.

[4] American Psychiatric Association. APA (2013). Diagnostic and Statistical Manual of Mental Disorders. 2010;5.

[5] Brownley KA, Berkman ND, Peat CM, Lohr KN, Cullen KE, Bann CM, Bulik CM. Binge-eating Disorder In Adults: A Systematic Review and MetaAnalysis. Annals of Internal Medicine. 2016 Sep 20;165(6):409-20.

[6] Goldschmidt AB, Lavender JM, Hipwell AE, Stepp SD, Keenan K. Emotion Regulation and Loss of Control Eating in Community-based Adolescents. Journal of Abnormal Child Psychology. 2017 Jan $1 ; 45(1): 183-91$.

[7] Sonneville KR, Horton NJ, Micali N, Crosby RD, Swanson SA, Solmi F, Field AE. Longitudinal Associations Between Binge Eating and Overeating and Adverse Outcomes Among Adolescents and Young Adults: Does Loss of Control Matter?. JAMA Pediatrics. 2013 Feb 1;167(2):149-55.

[8] Fairburn CG, Shafran R, Cooper Z. A Cognitive Behavioural Theory of Anorexia Nervosa. Behaviour Research and Therapy. 1999 Jan 1;37(1):1-3.

[9] Slade P. Towards A Functional Analysis of Anorexia Nervosa and Bulimia Nervosa. British Journal of Clinical Psychology. 1982 Sep;21(3):167-79.

[10] Tiggemann M, Raven M. Dimensions of Control In Bulimia and Anorexia Nervosa: Internal Control,
Desire for Control, Or Fear of Losing Self-control? Eating Disorders. 1998 Jan 1;6(1):65-71.

[11] Casper RC, Hedeker D, McCLOUGH JF. Personality Dimensions in Eating Disorders and Their Relevance for Subtyping. Journal of the American Academy of Child \& Adolescent Psychiatry. 1992 Sep 1;31(5):830-40.

[12] King JA, Korb FM, Vettermann R, Ritschel F, Egner T, Ehrlich S. Cognitive Overcontrol as A Trait Marker in Anorexia Nervosa? Aberrant Taskand Response-Set Switching in Remitted Patients. Journal of Abnormal Psychology. 2019 Nov;128(8):806.

[13] Dawe S, Loxton NJ. The Role of Impulsivity in the Development of Substance Use and Eating Disorders. Neuroscience \& Biobehavioral Reviews. 2004 May 1;28(3):343-51.

[14] Monterosso J, Ainslie G. Beyond Discounting: Possible Experimental Models of Impulse Control. Psychopharmacology. 1999 Oct 1;146(4):339-47.

[15] Evenden JL. Varieties of Impulsivity. Psychopharmacology. 1999 Oct 1;146(4):348-61.

[16] Kane TA, Loxton NJ, Staiger PK, Dawe S. Does the Tendency To Act Impulsively Underlie Binge Eating and Alcohol Use Problems? An Empirical Investigation. Personality and Individual Differences. 2004 Jan 1;36(1):83-94.

[17] Waxman SE. A Systematic Review of Impulsivity in Eating Disorders. European Eating Disorders Review: The Professional Journal of the Eating Disorders Association. 2009 Nov;17(6):408-25.

[18] Eysenck SB, Eysenck HJ. Impulsiveness and Venturesomeness: Their Position in A Dimensional System of Personality Description. Psychological Reports. 1978 Dec;43(3_suppl):1247-55.

[19] Lowe MR, Eldredge KL. The Role of Impulsiveness in Normal and Disordered Eating.

[20] Rosval L, Steiger H, Bruce K, Israël M, Richardson J, Aubut M. Impulsivity in Women With Eating Disorders: Problem of Response Inhibition, Planning, Or Attention?. International Journal of Eating Disorders. 2006 Nov;39(7):590-3.

[21] Claes L, Vandereycken W, Vertommen H. Impulsivity-related Traits in Eating Disorder Patients. Personality and Individual Differences. 2005 Sep 1;39(4):739-49.

[22] Mallorquí - Bagué N, Vintró - Alcaraz C, Sánchez I, Riesco N, Agüera Z, Granero R, Jiménez Múrcia S, Menchón JM, Treasure J, Fernández Aranda F. Emotion Regulation As A 
Transdiagnostic Feature Among Eating Disorders: Cross - sectional and Longitudinal Approach. European Eating Disorders Review. 2018 Jan;26(1):53-61.

[23] Brockmeyer T, Holtforth MG, Bents H, Herzog W, Friederich HC. Lower Body Weight Is Associated With Less Negative Emotions in Sad Autobiographical Memories of Patients With Anorexia Nervosa. Psychiatry Research. 2013 Dec $15 ; 210(2): 548-52$.

[24] Evers C, Marijn Stok F, de Ridder DT. Feeding Your Feelings: Emotion Regulation Strategies and Emotional Eating. Personality and Social Psychology Bulletin. 2010 Jun;36(6):792-804.

[25] Harrison A, Sullivan S, Tchanturia K, Treasure J. Emotion Recognition and Regulation in Anorexia Nervosa. Clinical Psychology \& Psychotherapy: An International Journal of Theory \& Practice. 2009 Jul;16(4):348-56.

[26] Westwood H, Kerr-Gaffney J, Stahl D, Tchanturia K. Alexithymia in Eating Disorders: Systematic Review and Meta-analyses of Studies Using the Toronto Alexithymia Scale. Journal of Psychosomatic Research. 2017 Aug 1;99:66-81.

[27] Leehr EJ, Krohmer K, Schag K, Dresler T, Zipfel S, Giel KE. Emotion Regulation Model in Binge Eating Disorder and Obesity-A Systematic Review. Neuroscience \& Biobehavioral Reviews. 2015 Feb $1 ; 49: 125-34$

[28] Nicholls W, Devonport TJ, Blake M. The Association Between Emotions and Eating Behaviour in An Obese Population With Binge Eating Disorder. Obesity Reviews. 2016 Jan;17(1):30-42.

[29] Egan SJ, Wade TD, Shafran R. Perfectionism As A Transdiagnostic Process: A Clinical Review. Clinical Psychology Review. 2011 Mar 1;31(2):203-12.

[30] Hewitt PL, Flett GL, Turnbull-Donovan W, Mikail SF. The Multidimensional Perfectionism Scale: Reliability, Validity, and Psychometric Properties in Psychiatric Samples. Psychological Assessment: A Journal of Consulting and Clinical Psychology. 1991 Sep;3(3):464.

[31] Frost RO, Marten P, Lahart C, Rosenblate R. The Dimensions of Perfectionism. Cognitive Therapy and Research. 1990 Oct 1;14(5):449-68.

[32] Bardone-Cone AM, Wonderlich SA, Frost RO, Bulik CM, Mitchell JE, Uppala S, Simonich H. Perfectionism and Eating Disorders: Current Status and Future Directions. Clinical Psychology Review. 2007 Apr 1;27(3):384-405.

[33] Pratt EM, Telch CF, Labouvie EW, Wilson GT, Agras WS. Perfectionism in Women With Binge Eating Disorder. International Journal of Eating Disorders. 2001 Mar;29(2):177-86.

[34] Sassaroli S, Lauro LJ, Ruggiero GM, Mauri MC, Vinai P, Frost R. Perfectionism in Depression, Obsessive-compulsive Disorder and Eating Disorders. Behaviour Research and Therapy. 2008 Jun 1;46(6):757-65.

[35] Bizeul C, Brun JM, Rigaud D. Depression Influences the EDI Scores in Anorexia Nervosa Patients. European Psychiatry. 2003 May 1;18(3):119-23.

[36] Fairburn CG, Cooper Z, Shafran R. Cognitive Behaviour Therapy for Eating Disorders: A "Transdiagnostic" Theory and Treatment. Behaviour Research and Therapy. 2003 May 1;41(5):509-28. 